\title{
Ocular and vision defects in preschool children
}

\author{
Maureen Stayte, Barnaby Reeves, Catherine Wortham
}

\begin{abstract}
Ocular and/or vision defects are one of the commonest reasons for the referral of young children to hospital. In a survey of a birth cohort in one health district, $7 \cdot 1 \%$ of children were diagnosed as having such defects by their fifth birthday; $2.1 \%$ were detected before the age of 2 years, and $5 \cdot 1 \%$ between 2 and 5 years. Up to the age of 2 years, low birthweight children and those who require postnatal special care had a higher risk of having an ocular or vision defect diagnosed and were more likely to have serious visual impairment than other children. In contrast, between the ages of 2 and 5 years of age these high risk children showed no continuing increased risk of having a defect diagnosed, nor did they show any differences in the severity or type of vision defects compared with other children. Averaged over the years studied, the incidence of defects presenting to specialist eye clinics among all $2-5$ year olds was $1.7 \%$, higher than the $1.1 \%$ found for $0-2$ year olds. This increase consisted primarily of children with refractive errors only.

(Brf Ophthalmol 1993; 77: 228-232)
\end{abstract}

The assessment of need should be an integral part of planning the purchase and provision of appropriate health care services for a community. Diverse subpopulations exist within most communities and they may have widely varying needs depending, for example, on age. In the context of vision health care, young children are likely to have different requirements compared with adolescents, early presbyopes, or the elderly.

Ocular and/or vision defects are probably the commonest reason for the referral of preschool children to hospital, ${ }^{1}$ and consequently considerable health service resources are allocated for treatment of such conditions in this age group. This paper reports a survey of ocular and/or vision defects detected in a cohort of children born in 1984 and followed up until the age of 5 years. The aim of the study was to determine the demand incidence of different conditions in order to plan the efficient deployment of resources within the eye hospital and community services to meet the vision health care needs of preschool children.

Most research on the incidence of vision

Oxford Eye Hospital, Radcliffe Infirmary, Woodstock Road, Oxford OX2 6HE

M Stayte

B Reeves

C Wortham

Correspondence to:

Maureen Stayte.

Accepted for publication

6 January 1993 have investigated all vision defects. One was a cross sectional survey of 4 year olds 6 and the other was a longitudinal survey from birth to 6 years of age. ${ }^{7}$ in young children has focused strabismus and amblyopia. ${ }^{2-5}$ Although other defects are less common, they may account for a disproportionate amount of resources and result-
Different subgroups within an age group may also have varying requirements - for example, on account of previous medical history. A previous paper, ${ }^{8}$ which reviewed the cohort from birth up to 2 years of age (0-2 years), showed that 'high risk' children (infants of low birth weight and those who required admission to a special care nursery for longer than 24 hours in the neonatal period) have an increased risk of an ocular or vision defect, although the high risk group accounted for only $15 \%$ of all defects detected. High risk children were at particular risk of specific severe types of defect, especially of neurological origin. Many of these patients presented with heterotropia which was most frequently attributed to cerebral palsy.

This paper concentrates on data collected from the continued follow up of the 1984 birth cohort up to 5 years of age (2-5 years). Comparisons are also made between the data for $0-2$ year olds and 2-5 year olds. The following questions were of particular interest with respect to the planning of appropriate vision care provision for preschool children.

Firstly, in view of previous evidence of the increased incidence of ocular/vision defects in high risk children, ${ }^{8}$ we were concerned to investigate whether such children continue to show a significantly higher incidence of vision defects.

Secondly, we wanted to document the incidence of ocular/vision defects throughout the preschool period and to investigate whether the spectrum of defects changes as children become older. For example, previous studies have shown that the incidence of strabismus changes during early childhood, ${ }^{2-49}$ although there is some disagreement about the age at which incidence peaks. (Since most of the studies report rates of presentation for treatment, it is perhaps not surprising to find variation across studies since estimates will depend on the methods and timing of programmes for detection.) From the point of view of service planning, it is also important to consider the proportion of all ocular/vision defects accounted for by each condition, in addition to the incidence of particular conditions.

Related to the changing spectrum of defects with age, it was also of interest to record the most common sources of referral for a specialist ophthalmic opinion. A knowledge of the professional groups most likely to be seeing and referring children allows targeting of any future resource investment to improve the provision of care. One would expect manifest congenital defects to be detected at an early age by paediatricians, general practitioners, and clinical medical officers, with more subtle defects being detected by orthoptists at a later age (frequently when visual acuity testing becomes possible). 
We were not aware of any previous studies which have reported this information.

Finally, with a view to quality control, we wanted to find out whether there was any evidence that severe defects were being missed between 0 to 2 years of age. A secondary orthoptic vision screening (OVS) programme, which has been operating in the district since 1977, has been shown to reduce false positive hospital referrals in this age group. ${ }^{10}$ The current study offered the opportunity to check whether the reduction in false positives was being achieved at the cost of an increase in false negatives - that is, cases which remained undetected until an older age.

\section{Method}

The methodology for this study was the same as for a previous 0-2 year old birth cohort study, thereby allowing the data from the two studies to be aggregated and compared. Information was collected on all 2-5 year old children who were born in 1984 and were resident in the Oxfordshire health district at the time of referral to an eye clinic for a specialist ophthalmic opinion. As in the previous study, the population was divided into 'high' and 'low' risk groups:

1. The high risk group consisted of children of low birth weight and children who required admission to the special care nursery for longer than 24 hours during the neonatal period. These children were identified through the Oxford Region Register of Early Childhood Impairments (ORRECI). ${ }^{11}$

2. The low risk group consisted of all other children in the birth cohort.

Although OPCS data suggest that there is a slight net gain of preschool children through migration into Oxfordshire each year, ${ }^{12}$ for the purposes of the study it was assumed that the population movement into and out of the district was approximately the same. All children who moved into the study area and who had previously diagnosed ocular defects were excluded from the study. Children who moved into the area and who were subsequently referred to an eye clinic for the first time were included. They were classified as high or low risk on the basis of their previous medical histories, as indicated above.

All new patients born in 1984 , who were aged between 2 and 5 years when referred to orthoptic clinics within the Oxfordshire district for diagnosis and treatment, were identified. Ophthalmic data, medical history, source of referral, etc, were obtained from ophthalmic and orthoptic hospital records. Other data - for example, details of blind registrations in the 0-5 year old age group, were obtained from social services and paediatric assessment centres to ensure that no children with vision defects were overlooked. The following data were extracted from records:

(a) residence at the time of referral

(b) age of referral

(c) birth history

(d) source of referral

(e) outcome of referral and diagnosis.

Children were not included in the study if they had been referred (a) to hospital eye service clinics or accident and emergency departments with conditions such as conjunctivitis or blocked tear ducts, or (b) to orthoptic clinics solely for visual acuity testing or for sibling vision screening.

A case was defined as a child with a recognised or suspected ocular or vision abnormality which required treatment or surveillance. Thus, for the purposes of the study, asymptomatic children with small degrees of heterophoria which did not warrant specialist ophthalmic follow up or optical correction were considered to have no defect. Children with amblyopia were classified according to the putative cause - that is squint, refractive error, or cataract. There were no children with a marked unexplained reduction in visual acuity in the cohort; children with minor unexplained reductions in visual acuity who were followed up were classified as requiring surveillance.

\section{Results}

Table 1 gives details of the numbers of high and low risk children who had different types of vision and ocular defects first diagnosed between their second and fifth birthdays. In contrast to

Table 1 Numbers of high and low risk children with ocular and vision defects diagnosed between 2 and 5 years of age. (Results for 0-2 year olds have been published previously)

\begin{tabular}{|c|c|c|c|c|}
\hline \multirow[b]{2}{*}{ Type of vision defect } & \multicolumn{3}{|c|}{ Number (rate/ 1000 survivors at 5 years) } & \multirow{2}{*}{$\begin{array}{l}\text { Relative risk } \\
(95 \% C L)\end{array}$} \\
\hline & High risk & Low risk & Total children & \\
\hline $\begin{array}{l}\text { Heterotropia (intermittent or constant) } \\
\text { Spectacles ordered } \\
\text { No spectacles ordered } \\
\text { Refractive error without heterotropia }\end{array}$ & $\begin{array}{l}3(18 \cdot 9) \\
4\end{array}$ & $100(23 \cdot 2)$ & $103(23 \cdot 0)$ & $\begin{array}{l}0.49(0 \cdot 1-1 \cdot 6) \\
1.58(0.6-4 \cdot 4)\end{array}$ \\
\hline 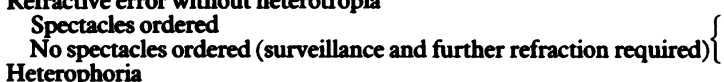 & $\begin{array}{l}4(10 \cdot 8) \\
0\end{array}$ & $127(22 \cdot 6)$ & $131(21 \cdot 9)$ & $0 \cdot 48(0 \cdot 2-1 \cdot 3)$ \\
\hline Spectacles ordered & $1(2 \cdot 7)$ & $\begin{array}{l}19(5 \cdot 2) \\
13\end{array}$ & $20(5 \cdot 1)$ & $0.51(0 \cdot 1-3 \cdot 8)$ \\
\hline $\begin{array}{l}\text { Periorbital pathology (including anomalies of lid, orbit, and } \\
\text { extraocular muscles) } \\
\text { Defects associated with neurological disease (including optic atrophy }\end{array}$ & $1(2 \cdot 7)$ & $5(1 \cdot 0)$ & $6(0.9)$ & $3 \cdot 31(0 \cdot 4-28 \cdot 4)$ \\
\hline $\begin{array}{l}\text { and cortical blindness) } \\
\text { Intraocular pathology (including congenital cataract and glaucoma) } \\
\text { Nystagmus }\end{array}$ & $1(2 \cdot 7)$ & $\begin{array}{l}0 \\
3(0 \cdot 5)\end{array}$ & $\frac{1}{3(0 \cdot 5)}$ & $\overline{-}$ \\
\hline $\begin{array}{l}\text { Manifest } \\
\text { Latest } \\
\text { Trauma (blowout fracture) } \\
\text { Total number of children with vision or ocular defect } \\
\text { Total number of children surviving in each groupt }\end{array}$ & $\begin{array}{l}1(2 \cdot 7) \\
0 \\
0 \\
14(37 \cdot 8) \\
370\end{array}$ & $\begin{array}{c}0(0 \cdot 2) \\
1 \\
1(0 \cdot 2) \\
318(52 \cdot 2) \\
6113\end{array}$ & $\begin{array}{c}1(0 \cdot 3) \\
1(0 \cdot 2) \\
332(51 \cdot 4) \\
6483\end{array}$ & $\begin{array}{l}16 \cdot 6(1: 0-265 \cdot 4) \\
\overline{0} \cdot 71(0 \cdot 4-1 \cdot 2)\end{array}$ \\
\hline
\end{tabular}

*Some.children had more than one defect. Therefore columns do not add up to these totals.

tChildren found to have a defect between 0-2 years are excluded from these totals. 


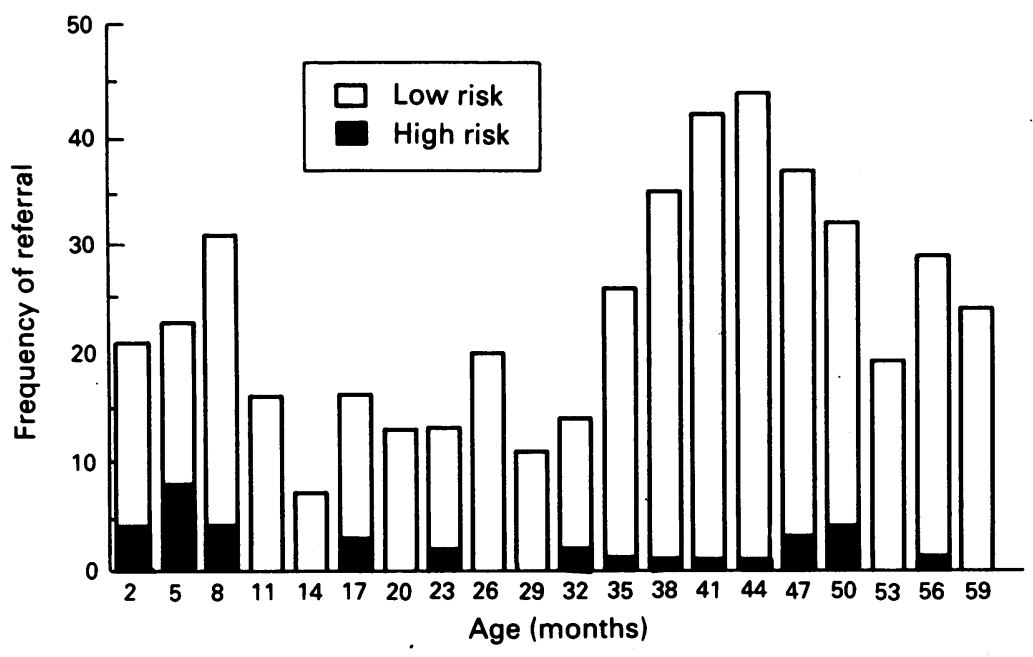

Figure 1 Numbers of 'high' and 'low' risk children referred at different ages between birth and 5 years of age.

the data from birth to 2 years of age (relative risk $2 \cdot 8,95 \%$ confidence limits (CLs) 1.8 to $4.5^{8}$ ), there was no evidence that the 'high risk' children had an increased risk of having a vision defect diagnosed between these ages (relative risk $0 \cdot 7$, 95\% CLs 0.4 to $1 \cdot 2$ ).

Very few neurological vision defects were diagnosed between 2 and 5 years of age. If neurological and intraocular pathologies are considered serious, and other defects as less serious, significantly fewer serious defects $(n=4)$ were diagnosed between 2 and 5 years than between 0 and 2 years $\left(n=26 ; \chi^{2}=50.48\right.$, df $\left.1, p<0.001\right)$.

The annual incidence of all defects in the high risk group (averaged over the 2 and 3 years studied) dropped from $2 \cdot 7 \%$ in $0-2$ year olds to

Table 2 Number of instances of specific intraocular and periorbital pathologies in high $(H R)$ and low risk $(L R)$ children aged $0-2$ years and 2-5 years

\begin{tabular}{|c|c|c|c|c|}
\hline & \multicolumn{2}{|c|}{$0-2$ years } & \multicolumn{2}{|c|}{$2-5$ years } \\
\hline & $H R$ & $L R$ & $H R$ & $L R$ \\
\hline \multicolumn{5}{|l|}{ Intraocular pathologies } \\
\hline Lens opacities & 0 & 2 & $\mathbf{0}$ & 2 \\
\hline Congenital choroiditis & 0 & 1 & 0 & 0 \\
\hline $\begin{array}{l}\text { Unilateral microphthalmos and } \\
\text { coloboma }\end{array}$ & & & & \\
\hline coloboma & 0 & 1 & 0 & 0 \\
\hline Bilateral coloboma & 0 & 1 & 0 & 0 \\
\hline Congenital toxoplasmosis & 0 & 1 & 0 & $\mathbf{0}$ \\
\hline Depigmented iris & 0 & 1 & $\mathbf{0}$ & $\mathbf{0}$ \\
\hline \multicolumn{5}{|l|}{ Cataract and retinal detachment } \\
\hline secondary to trauma & 0 & 1 & $\mathbf{0}$ & 0 \\
\hline Retinopathy of prematurity (grade 4) & 1 & 0 & $\mathbf{0}$ & 0 \\
\hline Unilateral myelinated nerve fibres & 0 & 0 & $\mathbf{0}$ & 1 \\
\hline \multicolumn{5}{|l|}{ Periorbital pathologies } \\
\hline Unilateral ptosis & 0 & 5 & $\mathbf{0}$ & 1 \\
\hline \multicolumn{5}{|l|}{ Inferior oblique overaction (wth BSV in } \\
\hline primary position) & 0 & 3 & 1 & 1 \\
\hline Duane's syndrome & 0 & 2 & $\mathbf{0}$ & 0 \\
\hline Marcus Gunn syndrome & 0 & 2 & 0 & 0 \\
\hline Corectopia & 0 & 1 & $\mathbf{0}$ & $\mathbf{0}$ \\
\hline Brown's syndrome & 0 & i & 0 & 3 \\
\hline
\end{tabular}

BSV = binocular single vision.

Table 3 Numbers (\%) of high $(H R)$ and low risk $(L R)$ children aged 0-2 years and 2-5 years with heterotropia ${ }^{\star}$, heterophoria ${ }^{\star}$, refractive error, and other pathologies

\begin{tabular}{|c|c|c|c|c|c|c|}
\hline & \multicolumn{3}{|c|}{$0-2$ years } & \multicolumn{3}{|c|}{$2-5$ years } \\
\hline & $H R$ & $L R$ & Total & $H R$ & $L R$ & Total \\
\hline $\begin{array}{l}\text { Heterotropia } \\
\text { Heterophoria } \\
\text { Refractive error only + surveillance } \\
\text { Other pathologies }\end{array}$ & $\begin{array}{l}9(43) \\
2(9) \\
0(0) \\
10(48)\end{array}$ & $\begin{array}{l}74(63) \\
8(7) \\
9(8) \\
27(23)\end{array}$ & $\begin{array}{l}83(60) \\
9(6) \\
10(7) \\
37(27)\end{array}$ & $\begin{array}{l}7(50) \\
1(7) \\
3(21) \\
3(21)\end{array}$ & $\begin{array}{l}141(44) \\
32(10) \\
134(42) \\
11(3)\end{array}$ & $\begin{array}{r}148(45) \\
33(10) \\
137(41) \\
4(4)\end{array}$ \\
\hline Total cases & 21 & 118 & 139 & 14 & 318 & 332 \\
\hline
\end{tabular}

${ }^{\star}$ Heterotropia and heterophoria categories include only those children in whom these conditions were the primary pathologies
Table 4 Numbers (\%) of children diagnosed as having different types of heterotropia ${ }^{\star}$ and heterophoria ${ }^{\star}$ by age group

\begin{tabular}{llcc}
\hline & $0-2$ years & $2-5$ years & Total \\
\hline Heterotropia & & & \\
Constant & & & \\
Convergent & $47(57)$ & $120(81)$ & $167(72)$ \\
Divergent & $2(3)$ & $3(2)$ & $5(2)$ \\
Intermittent & $13(16)$ & $2(1)$ & $15(7)$ \\
Convergent & $21(25)$ & $23(16)$ & $44(19)$ \\
Divergent & 83 & 148 & 231 \\
Total & & & \\
Heterophoria & $8(89)$ & $22(67)$ & $30(71)$ \\
Esophoria & $1(11)$ & $11(33)$ & $12(29)$ \\
Exophoria & 9 & 33 & 42 \\
Total & & & \\
\hline
\end{tabular}

*Heterotropia and heterophoria categories include only those children in whom these conditions were the primary pathologies.

$1.3 \%$ in $2-5$ year olds, but increased in the low risk group from $0.9 \%(0-2$ years) to $1 \cdot 7 \%(2-5$ years). The overall incidence was high in the first . year of life $(1.37 \%, 95 \%$ CLs $1.09 \%$ to $1.65 \%)$, lower in years 2 and $3(0.75 \%, 95 \%$ CLs $0.54 \%$ to $0.96 \%$ and $1 \cdot 10 \%, 95 \%$ CLs $0.84 \%$ to $1.35 \%$ respectively) and higher again in years 4 and 5 (2.46\%, $95 \%$ CLs $2 \cdot 08 \%$ to $2 \cdot 84 \%$ and $1.63 \%$, $95 \%$ CLs $1.32 \%$ to $1.94 \%)$. By 5 years of age, $7 \cdot 10 \%$ (95\% CLs $6 \cdot 48 \%$ to $7 \cdot 72 \%$ ) of all children had been diagnosed as having an ocular or vision defect. Figure 1 shows the rate of presentation of ocular and vision defects during the first 5 years of life.

It was considered important to establish whether any serious vision defects had been overlooked by the primary vision care services provided for 0-2 year olds and, if so, why this might have occurred. There were only four serious defects referred between 2 and 5 years. One high risk child had a field defect resulting from a known neurological condition. The other three children had intraocular pathologies and were in the low risk group; two were found to have lens opacities and one had myelinated retinal nerve fibres (see Table 2).

There were also six cases of periorbital pathologies among the 2-5 year olds, which were likely to have been present from infancy (see Table 2). Five involved extraocular muscle abnormalities, but in all cases the children had binocular single vision in the primary position. The sixth child had a slight unilateral ptosis of unknown origin.

In order to look more closely at changes in the pattern of referrals by age, some defects were pooled to give four categories (see Table 3), (a) heterotropia, (b) heterophoria, (c) refractive error only, and (d) 'other' (which included 'serious' defects). Children with multiple defects were classified according to the most serious pathology. The pattern of defects was very different across the two age groups $\left(\chi^{2}=85 \cdot 79\right.$, df $3, p<0 \cdot 001$ ), resulting primarily from relatively fewer children diagnosed as having 'other' defects and more children with refractive errors only between $2-5$ years. There was also a suggestion that heterotropia was less likely to be diagnosed between 2 to 5 years than from birth to 2 years of age.

Table 4 gives a more detailed breakdown of the heterotropias and heterophorias diagnosed between $0-2$ years and $2-5$ years. There were 
Table 5 Source of referrals (\%) by type of defect for (a) 0-2 and (b) 2-5 year olds

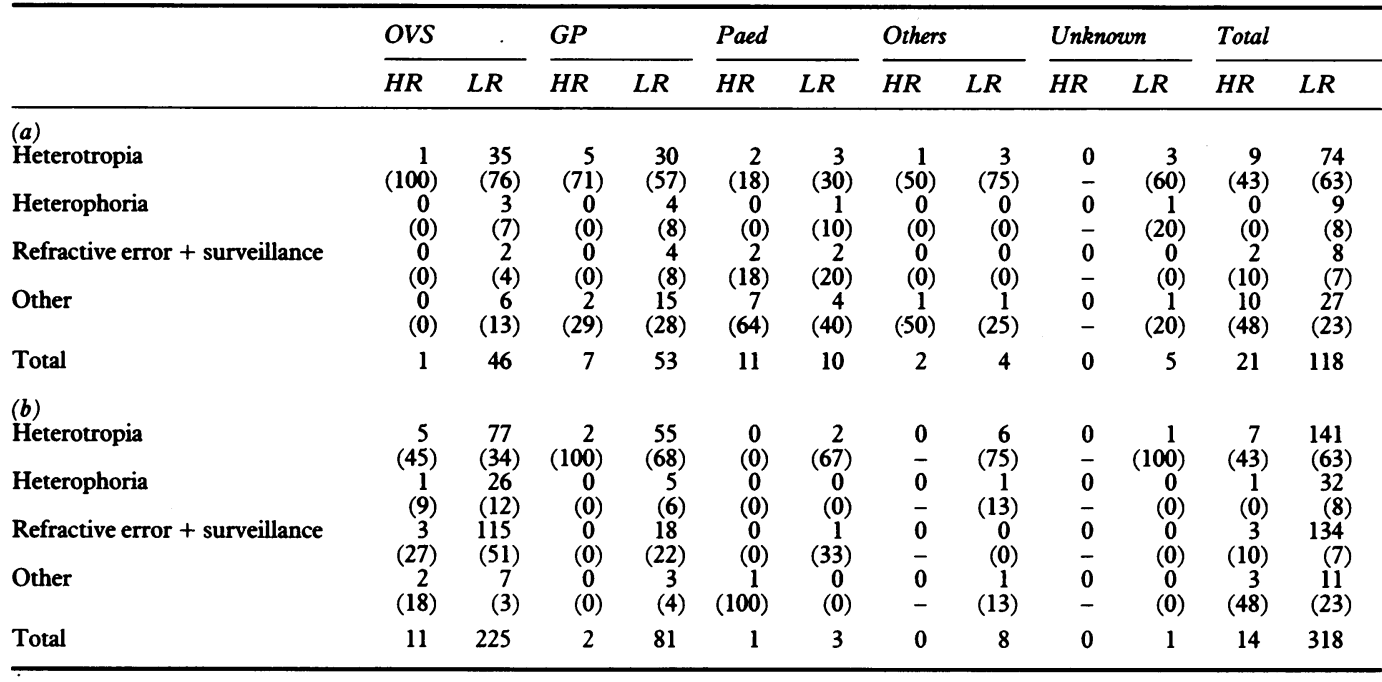

OVS=orthoptic vision screening; $G P=$ general practitioner; $P a e d=$ paediatrician; $H R=$ high risk; $L R=$ low risk.

many more convergent than divergent constant squints, but more divergent than convergent intermittent squints. The only significant difference between age groups was found for intermittent squints, there being relatively more intermittent convergent defects diagnosed between $0-2$ years than between $2-5$ years $\left(\chi^{2}=7 \cdot 28\right.$, df 1 , $\mathrm{p}<0.01$ ).

Table 5 shows the sources of referrals by age. A comparison of sources of referrals between age groups (pooled across high and low risk children), showed a significant difference $\left(\chi^{2}=64 \cdot 70\right.$, df $3, p<0.001)$. A much higher proportion of referrals between 2-5 years resulted from OVS, whereas general practitioners and paediatricians referred a higher proportion of $0-2$ year olds. There was also a significant difference between the sources of referrals for high and low risk children aged $0-2$ years $\left(\chi^{2}=30.73\right.$, df 3 , $\mathrm{p}<0.001$ ) but not for children aged $2-5$ years. Paediatricians referred a higher proportion of high risk 0-2 year olds (which were likely to be cases with serious defects), whereas general practitioners and OVS accounted for the majority of low risk referrals.

Table 6 shows the total number of referrals in the two age groups, divided into false positives (no defect found) and true positives. A significantly higher proportion of false-positives was referred between $0-2$ years than between $2-5$ years $\left(\chi^{2}=17 \cdot 50\right.$, df $\left.1, p<0 \cdot 001\right)$.

\section{Discussion}

The main aim of this survey was to document the way in which the spectrum of defects and the overall incidence of defects changes with age. Serious defects, detectable without the need of

Table 6 Outcome for all children in cohort

\begin{tabular}{lllr}
\hline Outcome & $\begin{array}{l}0-2 \text { years } \\
\text { cases }\end{array}$ & $\begin{array}{l}2-5 \text { years } \\
\text { cases }\end{array}$ & Total \\
\hline Number of live births & 252 & 470 & 6687 \\
Referred, no defect found & 113 & 138 & 251 \\
Referred, defect diagnosed & 139 & 332 & 471 \\
Not referred & $\overline{8}$ & $\overline{7}$ & 5900 \\
Deaths & 58 & & 65 \\
\hline
\end{tabular}

significant cooperation of the child, are more common in the first 2 years of life while more subtle defects, most notably refractive errors and heterophorias, are detected more often between 2 and 5 years of age, when it becomes possible to obtain subjective measurements of visual acuity and children are more likely to cooperate with examination techniques such as the cover test.

The survey was also intended to determine whether low birthweight children and those who required intensive care during the perinatal period continue to have a higher risk of ocular and vision defects being diagnosed after 2 years of age. Our data show clearly that this is not the case.

It should be pointed out that the estimates of the incidence of ocular and vision defects derived from the data are 'demand' incidences - that is, the incidences of children attending at eye clinics for a specialist ophthalmic or orthoptic opinion. Some children did not attend a clinic when they were referred. It is possible that these children were managed within the community by optometrists or were treated privately.

The proportion of preschool children in the Oxford health district with defects found in this study $(7 \cdot 1 \%)$ agrees well with the figure reported previously for Oxford city only (7.6\% for the same age group). ${ }^{7}$ Comparison with Kohler's study $^{16}$ is not straightforward because he used a cross-sectional survey method. Also, children were not followed up to obtain definitive diagnoses for suspects. Kohler ${ }^{1}$ reports an overall prevalence of ocular/vision defects of $8.9 \%$, although it is not clear which suspects are included to give this estimate. Accepting this figure, any difference is likely to reflect the way in which children with defects were detected. The current study estimated the demand incidence for the hospital eye service from children detected on referral, whereas Kohler's prevalence estimate was derived from a community-based study of all children. Thus Kohler's estimate may be a more representative figure for the overall prevalence of defects in the whole population, while our own is a more appropriate estimate for the planning of the district's vision care services. 
Given the changing incidence with age, the rate of referral merits closer scrutiny. From Figure 1, it can be seen that there are two referral peaks. The first occurs at $6-9$ months, and is presumably linked to vision screening carried out at 'well baby' clinics. A second peak occurs at about $\mathbf{4 2}$ months, which is considered to be the age when defects become more apparent because children are more easy to test, and when OVS (in Oxfordshire) has most impact with preschool children. This interpretation is supported by the fact that a much higher proportion of 2-5 year olds were referred through the OVS programme. In areas which do not have an OVS programme, the peak referral time may not be the same and the distribution of referral sources is also likely to differ. Interestingly, the bimodal pattern of incidence was not found in the previous study of defects in an Oxford city population of children born in 1978 and 1979, ${ }^{7}$ which showed a steady increase in incidence up to 5 years of age. The reason for this difference is not known, since there have been no changes in the vision screening programme for babies in the intervening period. It is possible that the increase in the number of defects detected in the first year of life reflects a heightened awareness of vision problems, resulting jointly from the ORRECI and improved communication between primary care teams and orthoptists carrying out the OVS programme.

A further concern at the outset was whether some children with serious or readily detectable defects were not being referred by paediatricians or were being missed by primary vision screening (primarily health visitors and general practitioners) for babies and infants. Although some children with neurological, intraocular, and periorbital defects did present when aged more than 2 years, it was considered that they were cases which required expert ophthalmic examination or reasonable cooperation from the child for detection.

The high risk child was already known to have multiple handicaps and was under paediatric care, but had not been referred for a specialist ophthalmic opinion at an earlier age. From case record examination it was also evident that the three remaining patients with serious defects did not constitute cases which had been missed by the primary vision care services during infancy. The two patients with lens opacities did not have dense congenital cataracts (corrected visual acuities $6 / 36,6 / 36$, and $6 / 6,6 / 5$ ), and were only detected when visual acuities could be obtained. The third low risk child had myelinated nerve fibres in one eye only (visual acuities 6/6, 1/60) and was also only detected when a visual acuity for the affected eye could be measured. While it is not possible to give a guarantee that serious cases are not missed during infancy, our data suggest that in Oxfordshire such occurrences are extremely rare.

The six cases with periorbital pathologies had binocular single vision (BSV) in the primary position and were therefore unlikely to be detected through vision screening at an earlier age. Because they had BSV, the delay in referral would not have affected the vision outcome. Consideration of the specific periorbital defects found in the 2-5 year olds suggests a possible reason why they were not detected earlier. All of the cases had pathologies affecting upward eye movements, which are more difficult to detect in infants for two reasons. Young children tend to move their heads rather than their eyes when asked to look up, and epicanthic folds can mask abnormal movements on elevation in adduction.

This paper has documented the changing pattern and incidence of ocular and vision defects during early childhood, information which is vital for planning the provision of vision care. We have continued to follow the birth cohort to 8 years of age and are currently collating similar data for the older children. We are also examining the types of treatment and the outcomes of treatment for different ocular and vision defects, in order to search for ways to achieve increases in efficacy and efficiency in the provision of vision care.

We are grateful to the staff of the orthoptic clinics, especially at Horton General Hospital, Banbury, and Wallingford Community Hospital, and the staff of medical records departments throughout the district for their assistance with this study. We would also like to thank all the ophthalmologists working in the Oxfordshire to thank all the ophthalmologists working in the Oxfords
health district for allowing us to collect data for their patients.

health district for allowing us to collect data for their patients.
Funds for the study were provided by Oxfordshire Health Funds for the study were provided
Authority District Research Committee.

High risk children were identified through the Oxford Regional Register of Early Childhood Impairments (previously the Oxford Region Child Development Project), which is funded by the Oxford Regional Health Authority

1 Kohler L. Early detection and screening programmes for children in Sweden. In: Macfarlane JA, ed. Progress in child health. Volume 1. Edinburgh: Churchill Livingstone, 1984: $230-42$.

2 Frandsen AD. Occurrence of squint. Acta Ophthalmol (Suppl) $1960 ; 62: 27-51$

3 Graham PA. Epidemiology of strabismus. Br 7 Ophthalmol 1974; 58: 224-31.

4 Catford J, Absolon MJ, Millo A. Squints - a sideways look. In: Macfarlane JA, ed. Progress in child health. Volume 1. Macfarlane JA, ed. Progress in child health.

5 Somersald M, Erkilla H. Children referred for pleoptic treatment. Acta Ophthalmol 1988; 66: 509-13.

6 Kohler L, Stigmar G. Vision screening of four year-old children. Acta Paediatr Scand 1973; 62: 17-27.

7 Kendall JA, Stayte MA, Wortham C. Ocular defects in children from birth to 6 years of age. Br Orthop $\mathcal{F} 1989 ; 46$ : 3-6.

8 Stayte $M$, Johnson A, Wortham C. Ocular and visual defects in a geographically defined population of 2-year-old children. BrF Ophthalmol 1990; 74: 465-8.

9 Duke-Elder S, Wybar K. System of ophthalmology. Vol VI Ocular motility and strabismus. London: Henry Kimpton, 1973: 584-5.

10 Stayte M, Wortham C, Reeves BC. Orthoptists reduce false positive referrals. Health Trends 1992; 24: 157-61.

11 Johnson A, King R. A regional register of early childhood impairments: a discussion paper. Community Med 1989; 11: impairm

12 Office of Population Censuses and Surveys. Migration analysis unit. OPCS Monitor, MN Series, 1986. 